The second part of the book is concerned with electromagnetic induction in the mantle and the oceans, produced by magnetic fluctuations. Highly detailed mathematical theories are developed to cover all the various cases, including the thin-sheet approximation to deal with ocean screening and the spherically symmetric model for the Earth as a whole.

The author's approach has been to survey the original papers, many of them his own, choosing certain of them for detailed exposition. Here I think Prof. Rikitake is open to criticism. The book would have benefited greatly from a more unified approach instead of the mixture of styles and notations resulting from adhering closely to the original sources. An important gain from this would have been a new emphasis on the fundamental principles. For example, the choice of particular papers given detailed analysis in the first section does not seem to me to be very sensible. Many pages are devoted to the rather unsatisfactory Inglis model for field production, while the basic papers of Bullard and Gellman and of Elsasser are given much less space. I also feel that if he had considered the overall logic of the book more carefully the author might then have included more discussions of the physics involved, rather than being carried away by the mathematics as sometimes happens in the present volume.

As the book stands it represents a fairly complete summary of the important work in this field. The list of references is excellent so that the reader may easily follow up any line which is not fully dealt with in the text. The diagrams are clear and the mathematics well produced. There are a few printing mistakes and in places the English is idiosyncratic, but this does not seriously detract from the general readability of the work. Prof. Rikitake has performed a useful service in gathering all this material together in one volume, but I feel the work would have boen more valuable if he had developed the subject logically from the physical background in his own way.

R. L. PARKER

\section{FLUID FLOW}

Flow Measurement by Square-edged Orifice Plate Using Corner Tappings

By W. J. Clark. Pp. xiii +226. (London and New York: Pergamon Press, Lt $\left.{ }^{\lambda} 1965.\right) 200 s$. net.

THE square-edged orifice plate meter is probably the simplest device available for metering the flow of fluid in a duct, and, for that reason, it is the rnost commonly used instrument. Large quantities of often valuable fluids can flow through such a meter and it is necessary to ensure that the orifice plate is correctly installed if the flow readings are to be accurate. This monogreph is the result of Dr. Clark's experience with vast numbers of such instruments in a large chemical works, and methods of designing such metering installations are described using charts and a special slide-rule to calculate the orifice diameter and flow characteristic. A number of specimen calculations and installations are included and the importance of regular maintenance is emphasized in what is essentially a practical approach to the subject.

It is inevitable that many of the data presented in the monograph are basically the same as those contained in the British Standard on flow measurement (B.S. 1042: 1964). The use in the text of non-standard Reynolds number correction factors could give rise to a little confusion, although this does perhaps illustrate the point that metering perfection cannot be expectod even under ideal laboratory conditions.

The monograph contains a fuller examination than is usual of tho influence of flow pulsations on metering errors, although it is a little disappointing that the author has not included references to the more recent work in this field. While Dr. Clark emphasizes that, in the majority of cases, errors due to this effect are negligible, the difficulty lies in detecting the presence of such errors. The cases brought to my notice have usually arisen where a user has observed a plant thermal efficiency greater than 100 per cent, or where the indicated flow is in the opposite direction to the known mean flow. Less extreme cases often go unnoticed, as a steady meter reading is so easily confusod with an accurate one. Dr. Clark devotes his attention mainly to the pulsation errors associated with the flow through the orifice or primary element, but the errors often spring from the manometer not indicating the true time mean of the pressure differential. Greater attention could have been given to the possible sources of these manometer errors and to the conditions necessary for their elimination. For example, the advice that damping should be confined to the manometer liquid rather than to the leads could be ehallenged, as linear damping devices in the leads near the orifice connexions can prove very successful in eliminating manometer errors. Symmetry in the manometer lines is no guarantee of accuracy since equal volumes in both lines can produce errors of the order of 100 per cent.

T. J. WILLIAMS

\section{ORGANOMETALLIC COMPOUNDS}

\section{Advances in Organometallic Chemistry}

Vol. 2. Edited by F. G. A. Stone and Robert West. Pp. ix +440 . (New York: Academic Press, Inc.; London: Academic Press, Inc. (London), Ltd., 1964.) 107s. 6d.

THE intensified study of organometallic compounds, as well as notable extensions in the field they embrace, makes the appearance of volumes such as this a dire necessity for chemists. Surely it is here, if anywhere, that all the main branches of chemistry meet and overlap. But perhaps for that very reason there is a subconscious tendency to regard organometallic chemistry as "nobody's baby", and nowhere has this been more apparent hitherto than among the compilers of reviews.

The present volume, under its able editorship, maintains the aims and standards of the first. The titles of the chapters are well chosen and avoid overlap with the first volume, but that is not to suggest that they fill in more than a very few of the gaps it left, and chemists will be hoping that this matter will in time be rectified by the due appearance of further volumes in fairly rapid succession. The one now presented is comprised of seven more or less extensive reviews written by specialists in the respective subjects, each review being subdivided into sections.

The alkali metals, nickel and boron, are particularly well represented. Indeed, well over half the book is devoted to some aspect of their chemistry, so that workers interested in these elements will find this volume especially important. It should be emphasized that the review by $\mathbf{R}$. Köster is not the same as that entitled "Organoboron heterocycles" which he published almost simultaneously in Prog. Boron Chem., 1, Chapter 7, but is quite different in presentation and to a large extent also in the material incorporated. The subject is in any case too vast to be conveniently covered by a single review, so that Köster's two reviews can be regarded as complementary.

The various chapters are not all equally exhaustive in the treatment of their subjects, but in this respect those by H. A. Skinner, R. B. King and J. Birmingham on the strengths of metal-carbon bonds, the reactions of alkali metal derivatives of metal carbonyls and related compounds, and on the synthesis of cyclopentadienyl metal compounds, respectively, may be singled out as coming to full comprehensiveness. It was almost inevitable that cyclopentadienyl and allyl complexes of nickel each come up for treatment in two different chapters, but otherwise there is no overlap. The chapters are all well written, and one is scarcely ever aware that English is not the mother tongue of several of the authors. Indeed, 